\title{
Developments in Transportation Geotechnics
}

\author{
J. T. Shahu ${ }^{1}$ G. L. Sivakumar Babu' ${ }^{2}$ Altaf Usmani ${ }^{3}$
}

Published online: 6 May 2020

(C) Indian Geotechnical Society 2020

Transportation geotechnics refers to all aspects of geotechnical engineering related to roads, railways, airfields and waterways. Rapid development of infrastructure, especially highways and railways, in developing nations has pushed up the need to find better design methodologies, improved construction procedures and new ecologically friendly construction materials. Continuous monitoring and performance evaluation are now important aspects of large infrastructure projects.

Most of the current flexible pavement design methods around the world follow a mechanistic-empirical approach. While AASHTO method is based on structural number $S N$, Indian Road Congress (IRC) method is based on limiting strains. IRC 37:2018 recommends keeping induced maximum vertical compressive strains on the subgrade surface and induced maximum horizontal tensile strains at the bottom of the bituminous layer below their corresponding limiting values to prevent subgrade rutting and fatigue cracking failures, respectively. While the induced strains are determined by considering individual pavement layers as linear elastic, the limiting values of the strains are obtained from empirical performance models.

In case of flexible pavements with granular layers (base and subbase) reinforced with geosynthetics, IRC: SP59

J. T. Shahu

shahu@civil.iitd.ac.in

1 Indian Institute of Technology Delhi, IIT Delhi, New Delhi, Delhi 110016, India

2 Indian Institute of Science, Bengaluru 560012, India

3 Engineers India Limited, Sector 16, Gurgaon, Delhi 122001, India recommends the use of layer coefficient ratios (LCR) or modulus improvement factor (MIF) to estimate improvement in resilient modulus of granular layer due to the geosynthetic reinforcement. For example, in case of reinforced subbase, first the resilient modulus of unreinforced subbase layer $\left(M_{\text {Run }}\right)$ is obtained as effective resilient modulus of subgrade layer $\left(M_{\mathrm{Rsg}}\right)$ multiplied by $\left(0.2 \times h^{0.45}\right)$, where $h$ is the thickness of subbase layer. The resilient modulus of reinforced subbase layer $\left(M_{\mathrm{Rrf}}\right)$ is then obtained from $M_{\text {Run }}$ and LCR (or MIF). LCR or MIF values can be obtained by detailed field and laboratory investigations.

India, like many other developing nations, has set ambitious targets of expansion of road and railway networks. A challenging problem in this regard is the widespread demand for pavement materials, which leads to fast depletion of natural aggregate resources. On the other hand, generation of huge amount of fly ash from thermal power plants and industrial wastes like slag from metal industries pose disposal problems such as shortage of land, and threat to public health and ecology. Bulk utilization of these wastes will not only protect fast depleting natural aggregate resources but also preserve valuable land and protect ecology and public health from huge waste dumps. Waste materials and marginal materials are also being utilized as backfill in reinforced soil walls. Research is needed to maximize the use of such waste products in pavement and track construction, and reinforced soil structures. This entails robust material testing, rational design methodologies, instrumentation, and performance and environmental monitoring.

This issue comprises of total fourteen articles (eleven papers and three technical notes) highlighting various 
aspects of transportation geotechnics, namely pavement monitoring, construction aspects, new materials, and geosynthetic reinforced pavements and soil structures.

Since road and railway projects stretch over long distances, it is desirable to have an efficient technology that can be used in the field to perform fast and frequent pavement inspection and monitoring. In the article "Evaluation of UAV-CRP Data for Monitoring Transportation Infrastructure Constructed over Expansive Soils," the authors have used Unmanned Aerial Vehicle-Close Range Photogrammetry (UAV-CRP) technique for health monitoring of pavements over problematic soils. They conclude that UAV-CRP-interpreted performance indicators show a very good agreement with those obtained from traditional surveys and profiler studies. The article "Application of Coir Geotextiles in Rural Roads in India" presents model tests and field trials to investigate the benefits of coir geotextiles in low volume roads on soft clayey soil subgrades. In "Experimental and Field Investigation of Road Mesh reinforcement in Flexible Pavements," the authors investigated the use of double twisted steel wire mesh as reinforcement material for base course and evaluated modulus improvement factor (MIF).

On railway track locations like approach to bridges, where the ballast layer is in direct contact with a stiff concrete base, progressive degradation of ballast is rapid. The article "Stabilization of Stiffer Rail Track Substructure using Artificial Inclusion" concludes that rubber mats placed underneath the ballast layer actively decrease the amount of strain energy transferred to the ballast layer, thus reducing particle degradation. In "The Use of Under Sleeper Pads to Improve Performance of Rail Tracks," the authors propose inclusion of energy absorbing rubber pads underneath the sleepers to mitigate ballast degradation of tracks over a stiff subgrade.

Six case histories - three on prefabricated vertical drains (PVD) with vacuum preloading and three on geosynthetic reinforced soil structures-are presented in "Case Histories on the Application of Vacuum Preloading and Geosynthetics Reinforced Soil Structures in Indonesia." The article "Geogrid Reinforced Soil Walls with Marginal Backfills Subjected to Rainfall: Numerical Study" presents the results of stability analyses coupled with transient seepage analyses to bring out the effect of rainfall on reinforced soil walls having poor-quality backfill soils. In
"Pseudo-static Analysis of Reinforced Soil Wall based on Pasternak Model," the authors present a mechanistic pseudo-static analysis of reinforced soil wall considering oblique pullout force. The article "Critical Appraisal of Shear Strength Parameters of In-situ Subsoil by SPT" presents the effect of different soil properties on shear strength parameters. The authors recommend the use of these correlations to check limiting values to be used in the design of bridge foundations where undisturbed samples from soil strata at great depths with high $N$-values are not possible to retrieve using conventional drilling methods.

The last five articles deal with the use of new or waste materials in place of conventional materials in roads and railway tracks. Based on extensive laboratory tests, the article "Physico-Chemical and Mechanical Characterization of Steel Slag as Railway Ballast" concludes that steel slag satisfies the standard requirements prescribed around the world for ballast material. The authors of "Replacement of Conventional Base Course with Stabilized Lateritic Soil using Granulated Blast Furnace Slag (GBFS) and Alkali" recommend that the base course of flexural pavements can be replaced with lateritic soil treated with $25 \%$ GBFS and alkali solutions containing $6 \% \mathrm{Na}_{2} \mathrm{O}$ and silica modulus of 1.0. In "Study on Pavement Soil Subgrade Properties with Reinforced Fibers," the authors conclude that the mechanical properties of subgrade soil show significant improvement when mixed with jute fibers or polypropylene fibers. The authors of "Applicability of Utilizing Stabilized Native Soil as a Subgrade Course in Flexible Pavement" conclude that the native expansive soil treated with 9-12\% GBFS and lime can be used as subbase course material. "Improvement in Subgrade Soils with Marble Dust for Highway Construction: A Comparative Study" shows that while the addition of marble dust increases the CBR of expansive black cotton soil, it is not so beneficial in case of sandy soil.

The aforesaid articles give a general flavor of broad field of transportation geotechnics and indicate where the field is headed. However, more research is needed in various sectors of transportation geotechnics to make the projects more sustainable, economical and environmental friendly.

Publisher's Note Springer Nature remains neutral with regard to jurisdictional claims in published maps and institutional affiliations. 